\author{
АВИАЦИОННАЯ И РАКЕТНО-КОСМИЧЕСКАЯ ТЕХНИКА \\ 05.07.01 - Аэродинамика и процессы теплообмена летательных аппаратов; \\ 05.07.02 - Проектирование, конструкция и производство летательных аппаратов; \\ 05.07.03 - Прочность и тепловые режимы летательных аппаратов; \\ 05.07.05 - Тепловые электроракетные двигатели и энергоустановки летательных аппаратов; \\ 05.07.07 - Контроль и испытание летательных аппаратов и их систем; \\ 05.07.09 - Динамика, баллистика, управление движением летательных аппаратов; \\ 05.07.10 - Инновационные технологии в аэрокосмической деятельности
}

UDC 681.5.017

DOI: $10.26467 / 2079-0619-2020-23-3-39-51$

\title{
FUNCTIONAL CONTROL OF THE TECHNICAL CONDITION METHOD FOR AIRCRAFT CONTROL SYSTEM SENSORS UNDER COMPLETE PARAMETRIC UNCERTAINTY
}

\author{
J.V. BONDARENKO ${ }^{1}$, E.YU. ZYBIN ${ }^{2}$ \\ ${ }^{1}$ Moscow State Technical University of Civil Aviation, Moscow, Russia \\ ${ }^{2}$ State Research Institute of Aviation Systems, Moscow, Russia
}

The study was conducted with the financial support of the Russian Foundation for Basic Research, grants №20-08-01215, №18-08-00453, №19-29-06091

\begin{abstract}
The control system sensors failures can cause the aircraft stability and controllability deterioration. Such failures fast and reliable inflight detection and localization allows minimization their consequences and prevention of an accident. Direct application of traditional parametric methods for sensors health monitoring with the use of their mathematical models is impossible due to the lack of information about the real inputs on their sensitive elements. This leads to the need for the problem of aircraft flight dynamics modeling with a high level of uncertainties to be solved, which complicates the application of functional test methods and determines the necessity of excessive sensors hardware redundancy. Widely known nonparametric methods either require a prior knowledge base, preliminary training, or long-term tuning on a large real flight data volume, or have low selective sensitivity for the failed sensors reliable localization. This paper expands the application of the well-known nonparametric failure detection criterion, based on the analysis of the linear dependence of the input-output data Hankel matrix columns and solution of the sensor failures localizing problem. Necessary and sufficient solvability conditions are given, the structure and the criterion values are determined in an analytical form before and after the failures occurrence. The proposed method does not require functional or hardware redundancy, prior information about the parameters of mathematical models and their stability, identification, observation, or prediction problems solution. The efficiency of the method is shown on the Boeing 747-100/200 longitudinal model example. Fast tuning, fast response and selective sensitivity of the developed algorithms are noted.
\end{abstract}

Key words: aircraft, control system, sensors, health monitoring, localization and detection failure, parametric uncertainty, nonparametric method.

\section{INTRODUCTION}

The necessity of aircraft operations safety improvement determines the relevance of developing algorithms which are able to detect onboard equipment and systems failures. Sensors direct and feedback aircraft control system connections failure, as a rule, cause changes in the structure of the aerodynamic relations of the aircraft, which may lead to deterioration of the aircraft stability and controllability characteristics. Rapid and reliable detection and localization of sensor failures in their technical condition monitoring process allows you to minimize undesirable consequences and take in-time measures to prevent an accident. 
All methods for detecting and localizing technical systems failures can be conditionally divided into two large groups [1-18]: parametricor model-based and nonparametric (parameter-free) or modelfree, which are also known as methods based on knowledge (knowledge-based), data (data-based, data-driven), signals (signal-based) or previous measurements (history-based).

Parametric (model) methods (such as: filtration, observation, forecasting, identification, parity relations, redundant variables, graph-theoretic methods, etc.) [5-7, 9-11] are the most widely spread methods and are considered to be the classical ones. These models either directly or indirectly utilize the real objects mathematical models parameters which values are set a priori based on the familiar physical operational guidelines or are evaluated during the identification process.

Direct use of parametric methods for monitoring the sensors technical conditionbased on their models is impossible due to the lack of information about the real signals input which their sensitive elements receive. This leads to the necessity of solution the aircraft flight dynamics modeling problem with a high level of uncertainty caused by non-linearity, unsteadiness, inaccuracy and nonidentifiability of mathematical models $[9,12,18]$. The resulting model errors inevitably cause an increase in the threshold values of the applied criteria, which increases the failures detecting and localizing time, it also reduces the reliability degree of the tasks to be solved. These problems impede the use of functional control methods and necessitate the use of flight parameters sensors hardware redundancy, which excess multiplicity is determined by the majority logic algorithms of the aircraft built-in control system.

Nonparametric methods do not require information about the parameters of the controlled objects models and are based on their input and output signals analysis measurements. Such methods are related to intelligent ones, since they consider the controlled object as a "black box" and make it possible to solve the problems for non-stationary and nonlinear systems under conditions of complete parametric uncertainty.

Widely known nonparametric methods based on knowledge (expert, neural network, genetic, fuzzy methods, support vector methods, etc.) $[1,5,8,13,14]$, do not use explicit system of models, but require a prior knowledge base, prior training, or long-term configuration on a large volume of real flight data. Nonparametric methods, which are completely based on signal analysis (methods for analyzing Hankel matrices, principal and independent components, statistical, factor, and cluster analysis, partial least squares, subspaces of states, blind identification, etc.) [1-7, 15-19], do not require any prior information about the object of control, while their configuration in real time requires a data preprocessing stage. These methods are characterized by high speed and reliability of failure detection, but they need additional transformations in order to localize them, since they have low selective sensitivity $[15,17]$.

This work continues research in the field of aircraft avionics technical condition monitoring and diagnosing by means of nonparametric methods and expands the application of the well-known failure detection criterion based on the input-output data Hankel matrix columns dependence analysis [15-17], and solution of the control system sensor failures localizing problem. The scope of the work is limited by the deterministic discrete stationary linear mathematical models of the controlled objects with completely measurable conditions.

\section{PROBLEM STATEMENT}

Let the dynamics of the aircraft with the functioning flight control system be described by a linear discrete model in the state space by the vector-matrix "input-state-output" form

$$
\begin{gathered}
x_{i+1}=A x_{i}+B u_{i}, \\
y_{i}=C x_{i}+D u_{i},
\end{gathered}
$$


where, $\mathrm{x}, \mathrm{y}, \mathrm{u}$ are vectors of states, measurements, and controls of dimensions $n_{x}, n_{y}$ and $n_{y}$ respectively; $A, B, C$, and $D$ are matrices of proper dynamics, control efficiency, measurements, and direct communication, respectively; and $i$-is the discrete moments of time.

Let's assume that at the moment of time $i=i_{f}$ there was a multiple simultaneous aircraft control system sensors failure type:

$$
y_{i}=F\left(C x_{i}+D u_{i}\right)=F C x_{i}+F D u_{i},
$$

where $F$ - is the failure matrix

$$
F=\operatorname{diag}\left(\left[\begin{array}{lllll}
f_{1} & \cdots & f_{k} & \cdots & f_{n_{y}}
\end{array}\right]\right)
$$

are the elements that characterize the sensor calibration violations at $f_{k} \neq 1 \neq 0$ /

Only relying on the results of the control vectors $u$ measurements and measurements $y$ without having information about the model $A, B, C, D$ parameters, it is necessary to determine the fact and time $i_{f}$ when the failure occurred, as well as to localize the measurement channels $k$ in which the sensors failed.

\section{FAILURES DETECTION PROBLEM SOLUTION}

Let's consider the time interval before failures occur when $i<i_{f}$. Let's write the expression (2) as a left-hand equation of the vector state observation.

$$
C x_{i}=y_{i}-D u_{i}
$$

It is known that any linear left-sided matrix equation of the $Q W=H$ form with known $Q, H$ matrices is solvable with respect to an unknown matrix $W$ when and only when the solvability condition is met [20].

$$
\bar{Q}^{L} H=0
$$

The entire set of solutions with minimal parameterization is described by the expression

$$
W=\tilde{Q} H+\bar{Q}^{R} \Psi
$$

where $\tilde{Q}=\tilde{Q}^{R} \tilde{Q}^{L}-$ is a generalized inverse matrix, $\tilde{Q}^{L}, \tilde{Q}^{R}-$ are left and right divisors of one, $\bar{Q}^{L}, \bar{Q}^{R}-$ are left and right divisors of null, that meet the conditions.

$$
Q^{L} Q Q^{R}=\left[\begin{array}{c}
\tilde{Q}^{L} \\
\bar{Q}^{L}
\end{array}\right] Q\left[\begin{array}{ll}
\tilde{Q}^{R} & \bar{Q}^{R}
\end{array}\right]=\left[\begin{array}{ll}
I & 0 \\
0 & 0
\end{array}\right],\left[\begin{array}{c}
\tilde{Q}^{L} \\
\bar{Q}^{L}
\end{array}\right]\left[\begin{array}{l}
\tilde{Q}^{L} \\
\bar{Q}^{L}
\end{array}\right]^{-1}=\left[\begin{array}{ll}
I & 0 \\
0 & I
\end{array}\right],\left[\begin{array}{ll}
\tilde{Q}^{R} & \bar{Q}^{R}
\end{array}\right]^{-1}\left[\begin{array}{ll}
\tilde{Q}^{R} & \bar{Q}^{R}
\end{array}\right]=\left[\begin{array}{ll}
I & 0 \\
0 & I
\end{array}\right],
$$

$Q^{L}, Q^{R}$ - are left and right canonizers that formalize direct and inverse Gauss transformations, $\Psi-$ is an arbitrary matrix.

Then, according to [6] while performing the condition of the equation solvability

$$
\tilde{C}^{L}\left(y_{i}-D u_{i}\right)=0
$$


let us define the state vector for the current and previous time points taking into account (7)

$$
\begin{gathered}
x_{i}=\tilde{C}^{L}\left(y_{i}-D u_{i}\right), \\
x_{i-1}=\tilde{C}^{L}\left(y_{i-1}-D u_{i-1}\right),
\end{gathered}
$$

which, according to (1) are also connected by the expression

$$
x_{i}=A x_{i-1}+B u_{i-1} \text {. }
$$

Let's substitute (10) and (11) into (12)

$$
\tilde{C}^{L}\left(y_{i}-D u_{i}\right)=A \tilde{C}^{L}\left(y_{i-1}-D u_{i-1}\right)+B u_{i-1} .
$$

and combine (13) and (9) into one system of matrix equations

$$
\left[\begin{array}{c}
\tilde{C}^{L} \\
\bar{C}^{L}
\end{array}\right]\left(y_{i}-D u_{i}\right)=\left[\begin{array}{l}
I \\
0
\end{array}\right]\left(A \tilde{C}^{L}\left(y_{i-1}-D u_{i-1}\right)+B u_{i-1}\right)
$$

and then multiply it on the left by the inverse matrix of the left canonizer

$$
y_{i}-D u_{i}=\left[\begin{array}{c}
\tilde{C}^{L} \\
\bar{C}^{L}
\end{array}\right]^{-1}\left[\begin{array}{l}
I \\
0
\end{array}\right] A \tilde{C}^{L}\left(y_{i-1}-D u_{i-1}\right)+\left[\begin{array}{c}
\tilde{C}^{L} \\
\bar{C}^{L}
\end{array}\right]^{-1}\left[\begin{array}{l}
I \\
0
\end{array}\right] B u_{i-1} .
$$

Having completely measurable $\bar{C}^{R}=0$ states, we can assume $C^{R}=I$ without loss of generality, and the inverse matrix in accordance with (8) takes the form of an identity

$$
\left[\begin{array}{l}
\tilde{C}^{L} \\
\bar{C}^{L}
\end{array}\right]^{-1}=\left[\begin{array}{ll}
\widetilde{C}^{L} & \widetilde{C}^{R}
\end{array}\right]
$$

the substitution of which into (14) leads to the expression

$$
y_{i}={\widetilde{\tilde{C}^{L}}}^{R} A \tilde{C}^{L} y_{i-1}+\left({\widetilde{\tilde{C}^{L}}}^{R} B-{\widetilde{\widetilde{C}^{L}}}^{R} A \tilde{C}^{L} D\right) u_{i-1}+D u_{i}
$$

which, with the account of the input-output matrix notation introduction

$$
z_{i}=\left[\begin{array}{c}
y_{i-1} \\
u_{i-1} \\
u_{i}
\end{array}\right]
$$

will take the compact form of an equivalent (1)-(2) aircraft flight dynamics model of the "inputoutput" type

$$
y_{i}=\Omega z_{i}
$$

where $\Omega=\left[\begin{array}{lll}\hat{A} & \hat{B} & \hat{D}\end{array}\right], \hat{A}={\widetilde{\tilde{C}^{L}}}^{R} A \tilde{C}^{L}, \hat{B}={\widetilde{\tilde{C}^{L}}}^{R} B-{\widetilde{\tilde{C}^{L}}}^{R} A \tilde{C}^{L} D, \hat{D}=D$ 
After the failure occurs, expression (3) can be written in the similar way as expression (2)

$$
y_{i}=C_{f} x_{i}+D_{f} u_{i}
$$

where $C_{f}=F C, D_{f}=F D$ - are the equivalent matrices of measurement and direct links. Then, taking into account the postulated at $f_{k} \neq 0$ failure matrix reversibility theaircraft flight dynamics model $\mathrm{F}$ at $i>i_{f}$ will take the form similar to (15)

$$
y_{i}=\Omega_{f} z_{i},
$$

where, $\Omega_{f}=\left[\begin{array}{lll}\hat{A}_{f} & \hat{B}_{f} & \hat{D}_{f}\end{array}\right], \hat{A}_{f}={\widetilde{\widetilde{C}_{f}^{L}}}^{R} A \tilde{C}_{f}^{L}, \hat{B}_{f}={\widetilde{\widetilde{C}_{f}^{L}}}^{R} B-{\widetilde{\widetilde{C}_{f}^{L}}}^{R} A \tilde{C}_{f}^{L} D_{f}, \hat{D}_{f}=D_{f}$.

Let us further assume that at the moment of time $i$ we also know $h-1$ of the previous signals values. Then we can write models (15) and (16) in matrix form

$$
\begin{gathered}
Y_{i}^{h}=\Omega Z_{i}^{h}, \\
Y_{i}^{h}=\Omega_{f} Z_{i}^{h},
\end{gathered}
$$

where $Y_{i}^{h}=\left[\begin{array}{llll}y_{i-h+1} & \cdots & y_{i-1} & y_{i}\end{array}\right], Z_{i}^{h}=\left[\begin{array}{llll}z_{i-h+1} & \cdots & z_{i-1} & z_{i}\end{array}\right]$.

Any linear right-sided matrix equation of the $W Q=H$ form with known matrices $Q, H$, is solvable with respect to an unknown matrix $W$ if and only if the solvability condition is met [20]

$$
H \bar{Q}^{R}=0
$$

the entire set of solutions with minimal parameterization is described by the expression

$$
W=H \tilde{Q}+\Psi \bar{Q}^{L}
$$

Then, if we consider the expressions for $i<i_{f}$ and for $i_{f}+h-1 \leq i$ as right-sided equations with respect to unknown matrices of model parameters, we can see that according to them they have a single solvability condition

$$
Y_{i}^{h} \bar{Z}_{i}^{R}=0
$$

where $Z_{i}^{h}{\overline{Z_{i}^{h}}}^{R}=0$. The fulfillment of condition (20) guarantees the existence of linear matrix models of the (17) and (18) types that describe the control input and output data both before and after the failures occur at $i_{f}+h-1 \leq i<i_{f}$. However, in the period between these time intervals at $i_{f} \leq i<i_{f}+h-1$ , the aircraft flight dynamics cannot be described by means of any single model, such as

$$
Y_{i}^{h}=\Omega Z_{i}^{h}+\Delta Y_{i}^{h}
$$

where $\Delta Y_{i}^{h}$ - is the errors measurement matrix caused by failures, so the performance of (20) is violated.

$$
Y_{i}^{h}{\overline{Z_{i}^{h}}}^{R}=\Delta Y_{i}^{h}{\overline{Z_{i}^{h}}}^{R} \neq 0
$$


Therefore, the condition (22) can be used as a simple criterion for the aircraft control system sensors failures detection [15-17], the quantitative value of which for each moment of time is determined, for example, using the Frobenius matrix norm

$$
\varepsilon_{i}=\left|Y_{i}^{h} \overline{\left[\begin{array}{c}
Y_{i-1}^{h} \\
U_{i-1}^{h} \\
U_{i}^{h}
\end{array}\right]}\right|_{2}^{R}>\varepsilon_{\text {доп }} .
$$

Criterion (23) will be zero before and after the failure occurs, when the control data matrices do not contain distorted measurements, and it will exceed an acceptable value when the control window includes the moment when the failure occurred.

\section{THE SOLUTIONOF FAULT LOCALIZATION PROBLEM}

We'll show further that the condition for detecting sensor failures (22), if considered line by line, can also be used to solve the problem of the failed measurement channel locating. To do this, we define the structure and values of the matrix measurement error in (21).

We need to notice that at the exact moment of failure at $i=i_{f}$ the equivalent model of aircraft flight dynamics differs from both (15) and (16):

$$
y_{i}=F \Omega z_{i},
$$

therefore in the $i_{f} \leq i<i_{f}+h-1$ time period, the expression (21) according to (17), (18), (24) can generally have three different forms

$$
Y_{i}^{h}=\left[\begin{array}{lll}
\Omega Z_{i_{f}-1}^{h_{n}} & F \Omega z_{i_{f}} & \Omega_{f} Z_{i}^{h_{f}}
\end{array}\right]=\Omega\left[\begin{array}{lll}
Z_{i_{f}-1}^{h_{n}} & z_{i_{f}} & Z_{i}^{h_{f}}
\end{array}\right]+\left[\begin{array}{lll}
0 & \Delta y_{i_{f}} & \Delta Y_{i}^{h_{f}}
\end{array}\right],
$$

where $\quad Y_{i}^{h}=\left[\begin{array}{lll}Y_{i_{f}-1}^{h_{n}} & y_{i_{f}} & Y_{i}^{h_{f}}\end{array}\right], Z_{i}^{h}=\left[\begin{array}{lll}Z_{i_{f}-1}^{h_{n}} & z_{i_{f}} & Z_{i}^{h_{f}}\end{array}\right], \Delta Y_{i}^{h}=\left[\begin{array}{lll}0 & \Delta y_{i_{f}} & \Delta Y_{i}^{h_{f}}\end{array}\right], h_{f}=i-i_{f}$, $h_{n}=h-h_{f}=h+i_{f}-i-$ is the number of measurements before and after the failure occurrence moment, accordingly; $\Delta y_{i_{f}}=\Delta \Omega z_{i_{f}}, \Delta Y_{i}^{h_{f}}=\Delta \Omega_{f} Z_{i}^{h_{f}}$,

$$
\begin{gathered}
\Delta \Omega=(F-I)\left[\begin{array}{lll}
\hat{A} & C B-\hat{A} D & D
\end{array}\right], \\
\Delta \Omega_{f}=\left[\begin{array}{lll}
\hat{A}_{f}-\hat{A} & (F-I)(C B-\hat{A} D) & (F-I) D
\end{array}\right] Z_{i}^{h_{f}} .
\end{gathered}
$$

Then, taking into account (25), we can explicitly write the value of criterion (22)

$$
Y_{i}^{h}{\overline{Z_{i}^{h}}}^{R}=\Delta Y_{i}^{h}{\overline{Z_{i}^{h}}}^{R}=\left[\begin{array}{lll}
0 & \Delta \Omega z_{i_{f}} & \Delta \Omega_{f} Z_{i}^{h_{f}}
\end{array}\right]{\overline{\left[\begin{array}{c}
Y_{i-1}^{h} \\
U_{i-1}^{h} \\
U_{i}^{h}
\end{array}\right]}}^{R} .
$$


As it follows from (28), at the moment of failure at $i=i_{f}$ the necessary and sufficient provision for the condition (22) fulfillment in accordance with (26) is the sensor failures occurrence when $f_{k}-1 \neq 0$ :

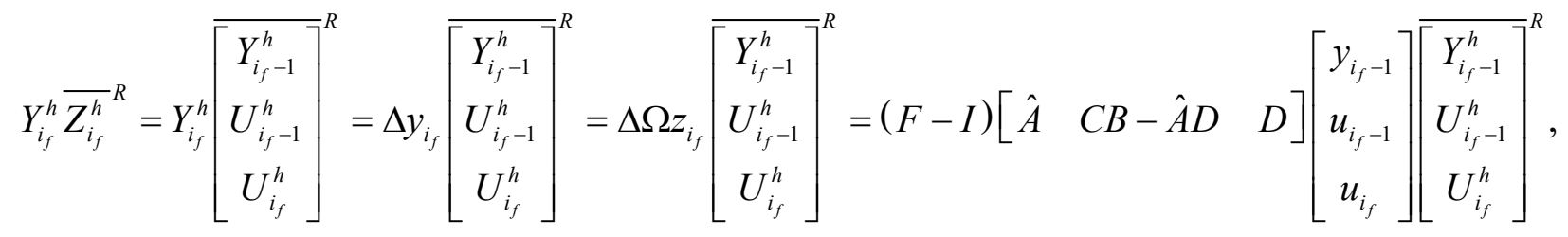

in that case, the quantitative criterion for detecting and localizing the $k$ sensor failure by analogy with (23) will have the form of

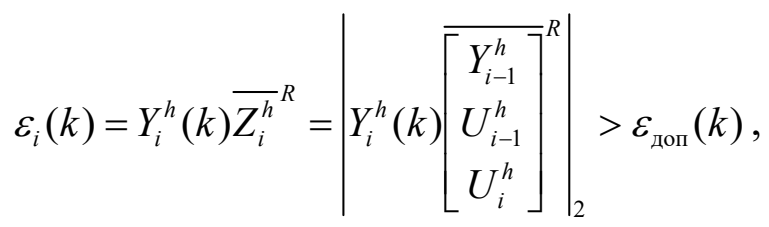

where $i=i_{f}, Y_{i}^{h}(k)-$ is the $k$ line of the $Y_{i}^{h}(k)$ matrix.

It should be noted that onwards during the $i_{f}<i<i_{f}+h-1$ time interval, the value of $\varepsilon_{i} \varepsilon_{i}(k)$ for functional sensors in the general case may also differ from zero due to the availability $\hat{A}_{f}-\hat{A}=F \hat{A} F^{-1}-\hat{A} \neq 0$ expression in (27), which's influence, as a rule, is tried to be eliminated while solving the problem of fault localization without taking into account $(29)[15,17]$. In particular cases when performing the identity

$$
\hat{A}=\hat{A}_{f}=F \hat{A} F^{-1},
$$

when, for example, its own dynamics matrix is equal to zero, has a diagonal form, or the failure leads to scaling of all measuring channels signals by the same gain coefficient, condition (22) retains its necessity and sufficiency for the entire control time interval. Moreover, while solving the practical problems, as it will be shown later, the value of the (29) criterion for functional channels measurement, as a rule, is several orders of magnitude lower than for channels with failed sensors. This fact is determined by the characteristic structure of the right zero divisor of the input-output Hankel matrix data, which analysis requires further theoretical and practical research.

\section{EXAMPLE OF THE PROBLEM SOLUTION}

In order to check the method efficiency, we'll analyze the solution of the flight sensors parameter technical condition functional controlproblem on the example of theBoeing 747-100/200 aircraft linearized continuous model longitudinal movement dynamics, which parameters in one of the flight modes have the form of [2] 


$$
\begin{aligned}
& A=\left[\begin{array}{rrrrr}
-0,4861 & 0,000317 & -0,5588 & 0 & -2,4 \cdot 10^{-6} \\
0 & -0,0199 & 3,0796 & -9,8048 & 8,98 \cdot 10^{-5} \\
1,0053 & -0,0021 & -0,5211 & 0 & 9,30 \cdot 10^{-6} \\
1 & 0 & 0 & 0 & 0 \\
0 & 0 & -92,6 & 92,6 & 0
\end{array}\right] \\
& B=\left[\begin{array}{rrrrrrrrr}
-0,1455 & -0,1455 & -0,1494 & -0,1494 & -1,2860 & 0,0013 & 0,0035 & 0,0035 & 0,0013 \\
0 & 0 & 0 & 0 & -0,3122 & 0,1999 & 0,1999 & 0,1999 & 0,1999 \\
-0,0071 & -0,0071 & -0,0074 & -0,0074 & -0,0676 & -0,0004 & -0,0004 & -0,0004 & -0,0004 \\
0 & 0 & 0 & 0 & 0 & 0 & 0 & 0 & 0 \\
0 & 0 & 0 & 0 & 0 & 0 & 0 & 0 & 0
\end{array}\right], \\
& C=\left[\begin{array}{rrrrr}
0 & 0 & 1 & 0 & 0 \\
0 & -0,0199 & 3,0796 & -9,8048 & 9,98 \cdot 10^{-5} \\
0 & 0 & 0 & 1 & 0 \\
1 & 0 & 0 & 0 & 0 \\
0 & 0 & -92,6 & 92,6 & 0 \\
0 & 0 & 0 & 0 & 1
\end{array}\right], D=\left[\begin{array}{rrrrrrrrr}
0 & 0 & 0 & 0 & 0 & 0 & 0 & 0 & 0 \\
0 & 0 & 0 & 0 & -0,3122 & 0,1999 & 0,1999 & 0,1999 & 0,1999 \\
0 & 0 & 0 & 0 & 0 & 0 & 0 & 0 & 0 \\
0 & 0 & 0 & 0 & 0 & 0 & 0 & 0 & 0 \\
0 & 0 & 0 & 0 & 0 & 0 & 0 & 0 & 0 \\
0 & 0 & 0 & 0 & 0 & 0 & 0 & 0 & 0
\end{array}\right], \\
& x=\left[\begin{array}{lllll}
\delta \omega_{z} & \delta V_{T A S} & \delta \alpha & \delta \vartheta & \delta h
\end{array}\right]^{\mathrm{T}} \quad u=\left[\begin{array}{lllllllll}
\delta_{\text {eir }} & \delta_{\text {eil }} & \delta_{\text {eor }} & \delta_{\text {eol }} & \delta_{s t} & \delta_{\text {eng } 1} & \delta_{\text {eng } 2} & \delta_{\text {eng } 3} & \delta_{\text {eng } 4}
\end{array}\right]^{\mathrm{T}}
\end{aligned}
$$

$y=\left[\begin{array}{llllll}\delta \alpha & \delta \dot{V}_{T A S} & \delta \vartheta & \delta \omega_{z} & \delta V_{z} & \delta h\end{array}\right]^{\mathrm{T}} \omega_{z}$ - is the angular pitch velocity (radiant per second), $V_{T A S}-$ is true air speed ( $\mathrm{m} /$ per second), $\alpha$ - is the angle of attack (radiant), $\vartheta$ - the pitch angle (radiant), $h$ - altitude (meters), $\dot{V}_{T A S}-$ acceleration $\left(\mathrm{m} / \mathrm{sec}^{2}\right), V_{z}$-vertical speed $(\mathrm{m} / \mathrm{sec}), \delta_{e i r}, \delta_{e i l}, \delta_{e o r}, \delta_{e o l}-$ left and right inboard and outboard elevators angular deflection (radiant), $\delta_{s t}$ - stabilizer angular deflection (radiant), $\delta_{\text {eng1 }}, \delta_{\text {eng } 2}, \delta_{\text {eng3 }}, \delta_{\text {eng } 4}$ - engines 1-4 thrust guidance commands (radiant).

Let's simulate the airplane flight using the first-order Euler method with an integration step of $0,01 \mathrm{~s}$ and set at $i=0 \quad x_{0}=0$ the following control signals $x_{0}=0, \delta_{\text {stab }}=0^{\circ}, \delta_{\text {eng* }}=5^{\circ}$. We assume $\delta_{\text {eng* }}=5^{\circ}$ in accordance with (4) for single sensor failures models in every 0,05 second at $i_{f}^{\alpha}=0,1$, $i_{f}^{\dot{V}_{T A S}}=0,15, i_{f}^{\vartheta}=0,2, i_{f}^{\omega_{z}}=0,25, i_{f}^{V_{z}}=0,3, i_{f}^{h}=0,35$ and one multiple failure acceleration and pitch angular velocity sensor at $i_{f}^{\dot{V}_{T A S}}=i_{f}^{\omega_{z}}=0,4$.

Figure 1 shows graphs of measurement errors $\Delta y_{i}$ caused by sensor failures and (29) criteria for the width of the control window $h=10$. The analysis of the results shows that the absolute changes in the values on the charts at the time of failure are comparable, which determines the high relative sensitivity of criterion (29). It took only 7 measurements or $0,07 \mathrm{~s}$ to set up the algorithm before the dependent columns appeared in the data matrix. Both single and multiple sensor failures are detected and localized instantly as distorted measurement data is received. At the same time, as it was noted above, the values of the (29) criterion at $i>i_{f}$ for operable channels were indistinguishable from the calculation errors at this scale, despite the failure of (30) condition meeting. 

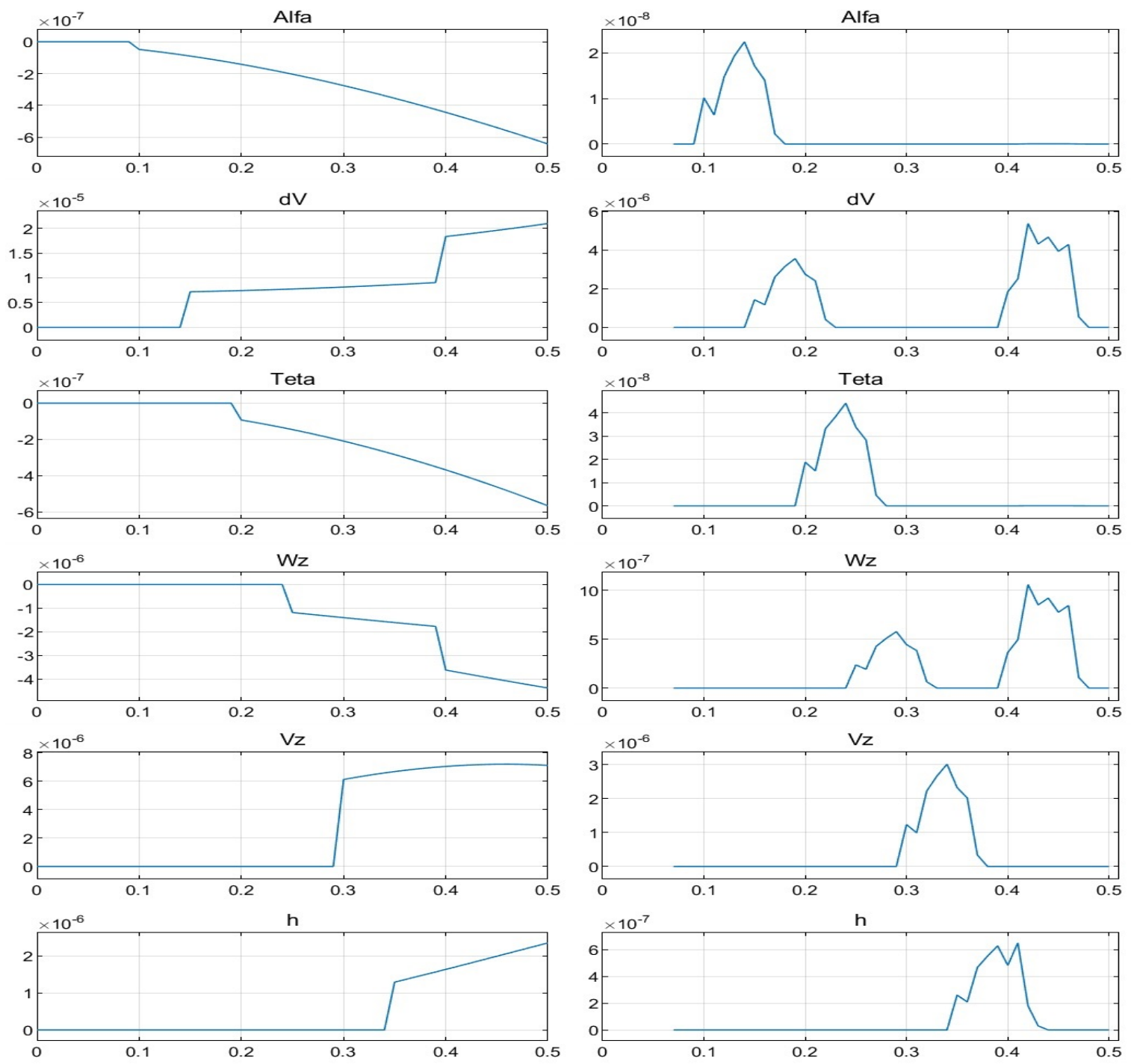

a) Calculation errors

b) Detection and localization criterion

Fig.1. Results of the computer simulation

\section{CONCLUSION}

The result of the conducted research, shows that the failure detection criterion based on the analysis columns linear dependence of the input and output Hankel matrix system data can be used for reliable localization of the failed measurement channel right at the moment when the sensors fail. The structure and importance of the before and afterfailure occurrence detection criteria are defined analytically. The required and adequate conditions for the fault localization problem solution existence are given.

The proposed method of functional detection and localization of the aircraft control system sensors failures in flight is only based on the analysis of its regular input and output signals and does not require functional or hardware redundancy, solution, observation or forecasting of identification problems. It is not affected by model errors, since it does not require information about the parameters of the aircraft model, while, unlike similar nonparametric methods, it does not use logical or statistical calculations, training, or long-term configuration, and can be used to solve problems of technical condition control in the state of complete parametric uncertainty, even in cases of instability and non- 
identificability of the aircraft mathematical model. The efficiency of the method is shown by means of the heavy mainline aircraft longitudinal movement linear model example. Fast configuration of the developed algorithms, instant failures detection and localizationare noted, as well as high relative sensitivity of the criterion.

The Hankel matrices analysis methods can be used as a base for the unified mathematical apparatus of the hybrid active control systems synthesis $[1,2,8]$, based on the joint use of parametric (analyzing the dependence of data matrix rows) and nonparametric (analyzing the dependence of data matrix columns) methods. The practical implementation of such a system will increase the level of fault tolerance of aircraft control system with a reduced multiplicity of its elements hardware redundancy.

\section{REFERENCES}

1. Gertler, J. (2019). Fault detection and diagnosis in engineering systems. CRC Press, 504 p.

2. Edwards, C., Lombaerts, T. and Smaili, H. (2010). Fault tolerant flight control: a benchmark challenge. Springer-Verlag, Berlin, 560 p. DOI: 10.1007/978-3-642-11690-2

3. Fekih, A. (2014). Fault diagnosis and fault tolerant control design for aerospace systems: a bibliographical review. American Control Conference (ACC), IEEE, pp. 1286-1291. DOI: 10.1109/ACC.2014.6859271

4. Samy, I., Postlethwaite, I. and Gu, D.W. (2011). Survey and application of sensor fault detection and isolation schemes. Control Engineering Practice, vol. 19, issue 7, pp. 658-674. DOI: $10.1016 /$ j.conengprac.2011.03.002

5. Dai, X. and Gao, Z. (2013). From model, signal to knowledge: a data-driven perspective of fault detection and diagnosis. IEEE Transactions on Industrial Informatics, vol. 9, issue 4, pp. 2226-2238. DOI: 10.1109/TII.2013.2243743

6. Tidriri, K., Chatti, N., Verron, S. and Tiplica, T. (2016). Bridging data-driven and modelbased approaches for process fault diagnosis and health monitoring: A review of researches and future challenges. Annual Reviews in Control, vol. 42, pp. 63-81. DOI: 10.1016/j.arcontrol.2016.09.008

7. Gao, Z., Cecati, C. and Ding, S.X. (2015). A Survey of fault diagnosis and fault-tolerant techniques - Part I: Fault diagnosis with model-based and signal-based approaches. IEEE transactions on industrial electronics, vol. 62, issue 6, pp. 3757-3767. DOI: 10.1109/TIE.2015.2417501

8. Gao, Z., Cecati, C. and Ding, S.X. (2015). A survey of fault diagnosis and fault-tolerant techniques - Part II: Fault diagnosis with knowledge-based and hybrid/active-based approaches. IEEE transactions on industrial electronics, vol. 62, issue 6, pp. 3768-3774. DOI: $10.1109 /$ TIE.2015.2419013

9. Zolghadri, A. (2018). The challenge of advanced model-based FDIR for real-world flightcritical applications. Engineering Applications of Artificial Intelligence, vol. 68, pp. 249-259. DOI: 10.1016/j.engappai.2017.10.012

10. Lopes, P.V.P., Hsu, L., Vilzmann, M. and Kondak, K. (2019). Model-based sensor fault detection in an autonomous solar-powered aircraft. Proceedings of the $10^{\text {th }}$ Aerospace Technology Congress, FTF, no. 162, pp. 247-254. DOI: 10.3384/ecp19162029

11. Ansari, A. and Bernstein, D.S. (2016). Aircraft sensor fault detection using state and input estimation. American Control Conference (ACC), IEEE, pp. 5951-5956. DOI: 10.1109/ACC.2016.7526603

12. Zybin, E.Yu. (2015). On identifiability of closed-loop linear dynamical systems under normal operating conditions. IzvestiyaSFedU. Engineering Sciences, no. 4 (165), pp. 160-170. (in Russian)

13. Xu, S. (2019). A survey of knowledge-based intelligent fault diagnosis techniques. Journal of Physics: Conference Series, IOP Publishing, vol. 1187, no. 3: 032006, 6 p. DOI: 10.1088/1742$6596 / 1187 / 3 / 032006$ 
14. Swischuk, R. and Allaire, D. (2019). A machine learning approach to aircraft sensor error detection and correction. Journal of Computing and Information Science in Engineering, vol. 19, no. 4: 041009, 12 p. DOI: 10.1115/1.4043567

15. Zhirabok, A.N., Shumsky, A.E. and Pavlov, S.V. (2017). Diagnosis of linear dynamic systems by the nonparametric method. Automation and Remote Control, vol. 78, no. 7, pp. 1173-1188. (in Russian)

16. Ding, S.X. (2014). Data-driven design of fault diagnosis and fault-tolerant control systems, Springer-Verlag, London, 300 p. DOI: 10.1007/978-1-4471-6410-4

17. Hakem, A., Pekpe, K.M. and Cocquempot, V. (2013). Fault detection and isolation for switching systems using a parameter-free method. Diagnostics and Prognostics of Engineering Systems: Methods and Techniques, IGI Global, pp. 98-118. DOI: 10.4018/978-1-4666-2095-7.ch005

18. Wang, K., Chen, J. and Song, Z. (2017). Data-drivensensor fault diagnosis systems for linear feedback control loops. Journal of Process Control, vol. 54, pp. 152-171. DOI: 10.1016/j.jprocont.2017.03.001

19. Fravolini, M.L., Core, G.D., Papa, U., Valigi, P. and Napolitano, M.R. (2017). Datadriven schemes for robust fault detection of air data system sensors. IEEE Transactions on Control Systems Technology, vol. 27, no. 1, pp. 234-248. DOI: 10.1109/TCST.2017.2758345

20. Zybin, E.Yu., Misrikhanov, M.Sh. and Ryabchenko, V.N. (2004). O minimalnoy parametrizatsii resheniy lineynykh matrichnykh uravneniy [On minimal parameterization of solutions of linear matrix equations]. Vestnik of Ivanovo State Power Engineering University, no. 6, pp. 127-131. (in Russian)

\title{
INFORMATION ABOUT THE AUTHORS
}

Julia V.Bondarenko, Postgraduate Student, Moscow State Technical University of Civil Aviation.yuliavladislavovna@gmail.com.

Evgeniy Yu. Zybin, Doctor of Technical Sciences, The Head of Laboratory, State Research Institute of Aviation Systems, eyzybin@2100.gosniias.ru.

\section{МЕТОД ФУНКЦИОНАЛЬНОГО КОНТРОЛЯ ТЕХНИЧЕСКОГО СОСТОЯНИЯ ДАТЧИКОВ СИСТЕМЫ УПРАВЛЕНИЯ ВОЗДУШНОГО СУДНА В УСЛОВИЯХ ПОЛНОЙ ПАРАМЕТРИЧЕСКОЙ НЕОПРЕДЕЛЕННОСТИ}

\author{
Ю.В. Бондаренко ${ }^{1}$, Е.Ю. Зыбин ${ }^{2}$ \\ ${ }^{1}$ Московский государственный технический университет гражданской авиации, \\ 2. Москва, Россия \\ ${ }^{2}$ Государственный научно-исследовательский институт авиациионых систем, \\ 2. Москва, Россия
}

Исследование выполнено при финансовой поддержке РФФИ в рамках научных проектов № 20-08-01215, №18-08-00453, №19-29-06091

\footnotetext{
Отказы датчиков системы управления могут вызвать ухудшение характеристик устойчивости и управляемости воздушного судна. Быстрое и достоверное обнаружение и локализация таких отказов в полете позволяет минимизировать их последствия и предотвратить авиационное происшествие. Непосредственное использование традиционных параметрических методов контроля технического состояния датчиков с использованием их математических моделей невозможно ввиду отсутствия информации об истинных входных сигналах, поступающих на их чувствительные
} 
элементы. Это приводит к необходимости решения задачи моделирования динамики полета воздушного судна с высоким уровнем неопределённостей, что затрудняет использование функциональных методов контроля и обуславливает необходимость использования избыточного аппаратного резервирования датчиков. Широко известные непараметрические методы либо требуют наличия априорной базы знаний, предварительного обучения или длительной настройки на большом объеме реальных полетных данных, либо обладают низкой избирательной чувствительностью для достоверной локализации отказавших датчиков. В работе расширяется применение известного непараметрического критерия обнаружения отказов, основанного на анализе линейной зависимости столбцов матрицы Ганкеля входовыходных данных, на решении задачи локализации отказов датчиков. Приводятся необходимые и достаточные условия существования решения, в аналитическом виде определяется структура и значения критерия до и после возникновения отказов. Предлагаемый метод не требует функционального или аппаратного резервирования, априорной информации о параметрах математических моделей и их устойчивости, решения задач идентификации, наблюдения или прогнозирования. Работоспособность метода показана на примере линейной модели продольного движения самолета Боинг 747-100/200. Отмечается быстрая настройка, высокое быстродействие и избирательная чувствительность разработанных алгоритмов.

Ключевые слова: воздушное судно, система управления, датчики, контроль технического состояния, обнаружение и локализация отказов, параметрическая неопределенность, непараметрический метод.

\section{СПИСОК ЛИТЕРАТУРЫ}

1. Gertler J. Fault detection and diagnosis in engineering systems. CRC Press, 2019. 504 p.

2. Edwards C., Lombaerts T., Smaili H. Fault tolerant flight control: a benchmark challenge. Berlin: Springer-Verlag, 2010. 560 p. DOI: 10.1007/978-3-642-11690-2

3. Fekih A. Fault diagnosis and fault tolerant control design for aerospace systems: a bibliographical review // American Control Conference (ACC). IEEE, 2014. Pp. 1286-1291. DOI: 10.1109/ACC.2014.6859271

4. Samy I., Postlethwaite I., Gu D.W. Survey and application of sensor fault detection and isolation schemes // Control Engineering Practice. 2011. Vol. 19, iss. 7. Pp. 658-674. DOI: 10.1016/j.conengprac.2011.03.002

5. Dai X., Gao Z. From model, signal to knowledge: a data-driven perspective of fault detection and diagnosis // IEEE Transactions on Industrial Informatics. 2013. Vol. 9, iss. 4. Pp. 2226-2238. DOI: 10.1109/TII.2013.2243743

6. Tidriri K. Bridging data-driven and model-based approaches for process fault diagnosis and health monitoring: A review of researches and future challenges / K. Tidriri, N. Chatti, S. Verron, T. Tiplica // Annual Reviews in Control. 2016. Vol. 42. Pp. 63-81. DOI: $10.1016 /$ j.arcontrol.2016.09.008

7. Gao Z., Cecati C., Ding S.X. A Survey of fault diagnosis and fault-tolerant techniques Part I: Fault diagnosis with model-based and signal-based approaches // IEEE transactions on industrial electronics. 2015. Vol. 62, iss. 6. Pp. 3757-3767. DOI: 10.1109/TIE.2015.2417501

8. Gao Z., Cecati C., Ding S.X. A survey of fault diagnosis and fault-tolerant techniques Part II: Fault diagnosis with knowledge-based and hybrid/active-based approaches // IEEE transactions on industrial electronics. 2015. Vol. 62, iss. 6. Pp. 3768-3774. DOI: 10.1109/TIE.2015.2419013

9. Zolghadri A. The challenge of advanced model-based FDIR for real-world flight-critical applications // Engineering Applications of Artificial Intelligence. 2018. Vol. 68. Pp. 249-259. DOI: $10.1016 /$ j.engappai.2017.10.012

10. Lopes P.V.P. Model-based sensor fault detection in an autonomous solar-powered aircraft / P.V.P. Lopes, L. Hsu, M. Vilzmann, K. Kondak // Proceedings of the $10^{\text {th }}$ Aerospace Technology Congress. FTF, 2019. No. 162. Pp. 247-254. DOI: 10.3384/ecp19162029

11. Ansari A., Bernstein D.S. Aircraft sensor fault detection using state and input estimation // American Control Conference (ACC). IEEE, 2016. Pp. 5951-5956. DOI: 10.1109/ACC.2016.7526603 
12. Зыбин Е.Ю. Об идентифицируемости линейных динамических систем в замкнутом контуре в режиме нормальной эксплуатации // Известия ЮФУ. Технические науки. 2015. № 4 (165). C. 160-170.

13. Xu S. A survey of knowledge-based intelligent fault diagnosis techniques // Journal of Physics: Conference Series. IOP Publishing. 2019. Vol. 1187, no. 3: 032006. 6 p. DOI: 10.1088/17426596/1187/3/032006

14. Swischuk R., Allaire D. A machine learning approach to aircraft sensor error detection and correction // Journal of Computing and Information Science in Engineering. 2019. Vol. 19, no. 4: 041009. 12 p. DOI: $10.1115 / 1.4043567$

15. Жирабок А.Н., Шумский А.Е., Павлов С.В. Диагностирование линейных динамических систем непараметрическим методом // АиТ. 2017. № 7. С. 3-21.

16. Ding S.X. Data-driven design of fault diagnosis and fault-tolerant control systems. London: Springer-Verlag, 2014. 300 p. DOI: 10.1007/978-1-4471-6410-4

17. Hakem A., Pekpe K.M., Cocquempot V. Fault detection and isolation for switching systems using a parameter-free method. Diagnostics and Prognostics of Engineering Systems: Methods and Techniques. IGI Global, 2013. Pp. 98-118. DOI: 10.4018/978-1-4666-2095-7.ch005

18. Wang K., Chen J., Song Z. Data-driven sensor fault diagnosis systems for linear feedback control loops // Journal of Process Control. 2017. Vol. 54. Pp. 152-171. DOI: $10.1016 /$ j.jprocont.2017.03.001

19. Fravolini M.L. Data-driven schemes for robust fault detection of air data system sensors / M.L. Fravolini, G.D. Core, U. Papa, P. Valigi, M.R. Napolitano // IEEE Transactions on Control Systems Technology. 2017. Vol. 27, iss. 1. Pp. 234-248. DOI: 10.1109/TCST.2017.2758345

20. Зыбин Е.Ю., Мисриханов М.Ш., Рябченко В.Н. О минимальной параметризации решений линейных матричных уравнений // Вестник ИГЭУ. 2004. № 6. С. 127-131.

\section{СВЕДЕНИЯ ОБ АВТОРАХ}

Бондаренко Юлия Владиславовна, аспирант, МГТУ ГА, yuliavladislavovna@gmail.com.

Зыбин Евгений Юрьевич, доктор технических наук, начальник лаборатории, ФГУП «Государственный научно-исследовательский институт авиационных систем» (ГосНИИАС), eyzybin@2100.gosniias.ru.

Поступила в редакцию

Принята в печать
16.03.2020

21.05.2020
Received

Accepted for publication
16.03 .2020

21.05.2020 